\title{
Independent Community Pharmacists' Experience in Offering Pharmacogenetic Testing
}

\author{
Susanne B Haga $\mathbb{D}$ \\ Rachel Mills $\mathbb{D}$ \\ Jivan Moaddeb \\ Yiling Liu \\ Deepak Voora
}

Center for Applied Genomics \& Precision Medicine, Durham, NC, 27708, USA
Correspondence: Susanne B Haga

Center for Applied Genomics \& Precision

Medicine, I0I Science Drive, Box 3382.

Durham, NC, 27708

Tel +919-684-0325

Email susanne.haga@duke.edu
Objective: This study assessed pharmacist experiences with delivering pharmacogenetic (PGx) testing in independent community pharmacies.

Methods: We conducted a cluster randomized trial of independent community pharmacies in North Carolina randomized to provide either PGx testing as a standalone service or integrated into medication therapy management (MTM) services. Surveys and pharmacist data about the delivery of PGx testing were collected. Semi-structured interviews were also conducted.

Results: A total of 36 pharmacists participated in the study from 22 pharmacies. Sixteen pharmacists completed the pre-study and post-study surveys, and four pharmacists completed the semi-structured interviews. Thirty-one percent (11/36) of pharmacists had had some education in personalized medicine or PGx prior to the study. The only outcome that differed by study arm was the use of educational resources, with significantly higher utilization in the PGx testing only arm $(\mathrm{p}=0.007)$. Overall, compared to the pre-study assessment, pharmacists' knowledge about PGx significantly improved post-study $(\mathrm{p}=0.018)$. In the post-study survey, almost all pharmacists indicated that they felt qualified/able to provide PGx testing at their pharmacy. While $75 \%$ of pharmacists indicated that they may continue to provide PGx testing at their pharmacy after the study, the major concerns were lack of reimbursement for PGx counseling and consultation given the necessary time required.

Conclusion: Our findings demonstrated a positive experience with delivering PGx testing in the community pharmacy setting with little difference in pharmacists' experiences in providing PGx testing with or without MTM. Pharmacists were confident in their ability to provide PGx testing and were interested in continuing to offer testing, though sustained delivery may be challenged by lack of prescribing provider engagement and reimbursement.

Keywords: pharmacy, pharmacogenetic testing, feasibility, pharmacist experience

\section{Introduction}

Currently, more than 300 prescription medications include information about pharmacogenetics in the US Food and Drug Administration-approved package insert. ${ }^{1}$ The US Clinical Pharmacogenetics Implementation Consortium (CPIC) has published 25 guidelines on the interpretation and application of pharmacogenetic (PGx) testing (as of 8 June 2021) and Dutch Pharmacogenetics Working Group has issued recommendations for 69 gene-drug combinations. As the evidence for clinical utility of PGx testing continues to expand, so have rapid and accurate testing platforms and commercial interest, leading to debate and exploration about effective options for delivery of PGx testing. ${ }^{2}$ Pharmacists are playing a leading role in the delivery of PGx testing ${ }^{3-6}$ and have been proactive in developing training 
opportunities and core curricula to prepare the pharmacist workforce to participate in this new professional role. ${ }^{7-9}$ Professional pharmacist organizations and accreditation bodies have also recognized the future role of the practice and have updated pharmacy school curricula so that all pharmacists have a minimal level of exposure to PGx content. ${ }^{10}$ Several surveys of pharmacists have reported enthusiasm for testing and provision of PGx services, but raise concerns about their knowledge/preparedness and reimbursement. ${ }^{11-14}$

The pharmacist delivery model may be implemented in different settings, such as hospitals, ${ }^{15}$ community pharmacies, ${ }^{16}$ clinical offices, ${ }^{17}$ and nursing homes. ${ }^{18}$ In addition, pharmacists may assist in the delivery of PGx testing through a PGx consultation service, ${ }^{19,20}$ specifically assisting with test ordering and interpretation of test results. PGx testing offered in combination with medication therapy management (MTM) allows careful consideration of the patient's medication history, adverse experiences, and both drug-drug and drug-gene interactions. $^{21,22}$ Additionally, the incorporation of PGx allows for the identification of clinically important drugdrug interactions through recognition of phenoconversion. ${ }^{23}$ Pharmacist-delivered PGx testing with MTM has been reported to reduce costs for elderly patients. $^{24}$

Although PGx testing has been clinically available for many years, there remains many barriers to the implementation of PGx testing including evidence of clinical utility of testing, provider preparedness, integration of testing into clinical workflow, clinical decision support, reimbursement, and availability of patient resources to promote comprehension and engagement. ${ }^{25}$ Each clinical setting will likely raise unique barriers to implementation. In this study, we assessed the feasibility of pharmacistdelivered PGx testing in an independent community pharmacy setting. As part of the study, we surveyed participating pharmacists before and after the study and conducted semi-structured interviews. Our findings may inform methods of increasing the involvement of community pharmacists in the delivery of PGx testing through identification of some practice barriers in this setting.

\section{Methods}

\section{Overview}

Details of this study design have been previously described. ${ }^{26}$ In summary, a cluster randomized trial was conducted whereby independent community pharmacies were randomized to provide PGx testing or PGx testing with MTM. Buccal swab samples were collected from patients at the pharmacy who presented with a new or recent prescription for one of 10 drugs for which PGx recommendations are available and sent to Pathway Genomics for analysis. ${ }^{26}$ Participating patients and pharmacists were surveyed prior to and after the study (patient data published separately). The study protocol was approved by the Institutional Review Board of the Duke University Health System (Pro00068552) and registered in ClincalTrials.gov (NCT02937545). All participants were informed about the purpose of the study and written informed consent obtained prior to study commencement. The study was conducted in accordance with the Declaration of Helsinki. Data on patient participant experiences and outcomes will be reported in a separate publication.

\section{Pharmacist Sites}

Thirty-six pharmacists at 22 independently-owned community pharmacies across North Carolina participated in the study. The pharmacies were located across the state in 14 counties, with a concentration of 12 pharmacies in the central part of the state (Figure 1). Seven pharmacies (accounting for 13 pharmacist participants; four pharmacies from the PGx-only study arm) withdrew before the end of the study due to a low number of participants enrolled or changes to staffing and subsequent inability to fulfill requirements of the trial.

\section{Pharmacist Survey}

An online pre-study and post-study survey was administered to all participating pharmacists. The pre-study (baseline survey) was administered to all pharmacists prior to their attendance in continuing education (CE) training required of the study. The baseline survey assessed knowledge of and experience with PGx testing, comfort with integrating PGx testing into pharmacy practice, comfort discussing PGx testing with patients, and experience with patient education and MTM. Pharmacist and pharmacy practice data were also collected including number of years in practice, other pharmacy services offered, and estimated time to complete each service. At the completion of the study, we administered a follow-up survey to re-evaluate knowledge of PGx testing, comfort with integrating PGx testing into pharmacy practice and discussing PGx testing with patients, likelihood of adding PGx testing 


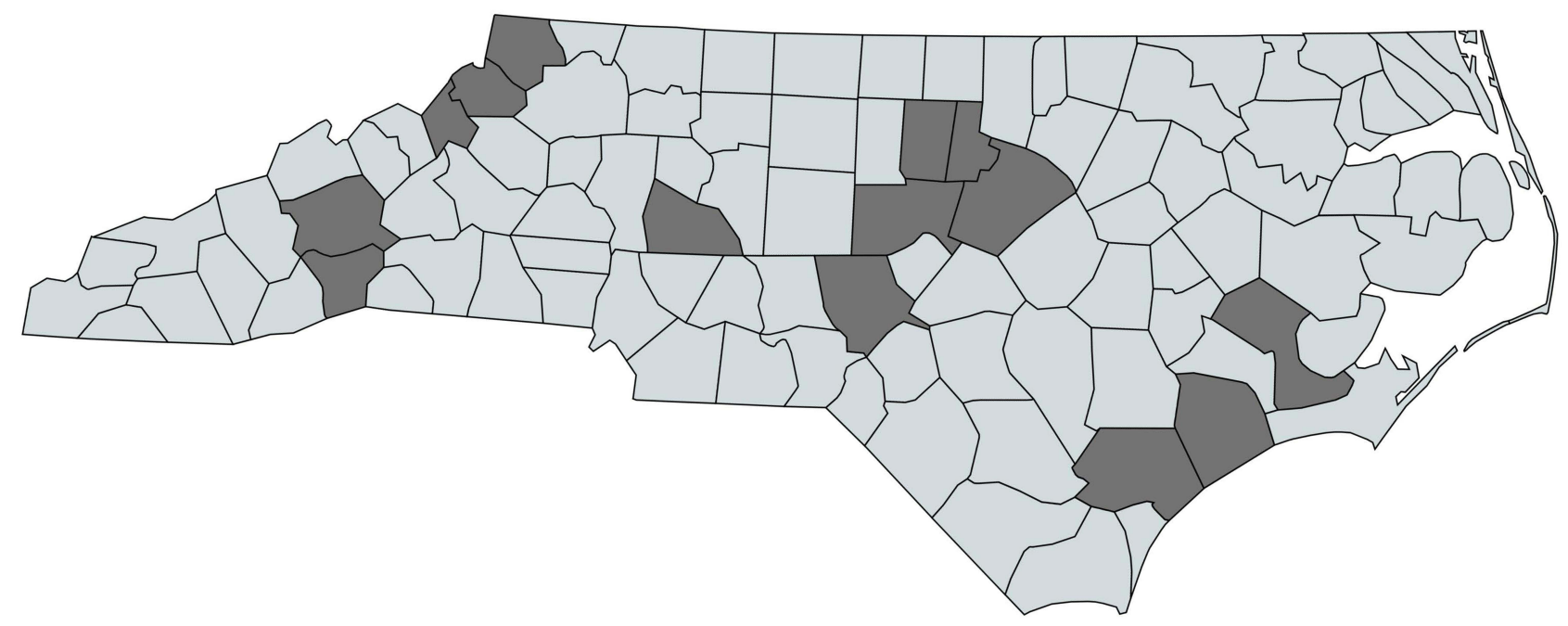

Figure I Map of the counties where the participating pharmacy sites are located across the state of North Carolina (US).

to their pharmacy services, and major barriers to implementation including potential impact of continuing a PGx service after the trial. All surveys were administered through REDCap, a secure web application for building and administering online surveys.

\section{Pharmacist Logbook}

We asked pharmacists to track their activities related to the study, particularly interactions with each patient and prescribing provider to enable analysis of feasibility of delivery of PGx testing in a pharmacy setting. In particular, we provided each pharmacy with a log sheet to record date/ time of each interaction, purpose of interaction, start and stop times, and mode of communication (in-person, phone, fax, email).

\section{Pharmacist Interviews}

Pharmacists were invited to participate in a semistructured phone interview to gather more in-depth feedback about their comfort and experiences with offering PGx testing in a pharmacy setting, how it was integrated into the workflow, and likelihood of continuing to offer PGx testing.

\section{Data Analysis}

Summary statistics were calculated for all survey questions. To test if the differences in responses by study arms as well as the demographic characteristics of the participants were independent of their tendency to complete both the pre- and post-testing survey, Fisher's exact test was applied for categorical variables, and exact Wilcoxon rank sum test for continuous variable. To test the association of pharmacists' pre-study PGx knowledge and their graduation year, an exact Wilcoxon rank-sum test was performed. An exact Wilcoxon signed-rank test was performed (a non-parametric test used for paired data) to test pharmacists' PGx knowledge before and after the study and the number of activities pre- and posttesting. All reported p-values are two-sided and were considered significant at a Type I error level of 0.05 . Given the small study population, we analyzed results both by study arm and in aggregate. All analysis were performed with R, with statistical tests using the stats and coin packages in $\mathrm{R}$.

For the interviews, transcripts were first reviewed to identify themes per question, and themes were coded. Given the small number of interviews, no additional analysis was performed by study arm. For the analysis of the logbooks, each entry in the logbook was reviewed and entered into the RedCap database. The study arm, pharmacy site, whether patient or provider-related activity, and date of the activity/interaction with respect to test completion (pre or post-testing) was recorded. Summary statistics were generated from the logbook analysis.

\section{Results}

\section{Study Population}

All 36 pharmacists who enrolled in the study completed the pre-study survey. A total of 13 pharmacists were based at one of the seven pharmacies that did not finish the study; of the 23 remaining pharmacists, 16 (70\%) completed the post-study survey. Pharmacist demographics were independent of their tendency to complete both the pre- and post-study surveys. At the start of the study, the 
median number of participating pharmacists per study site was one (range: 1 to 4 ; mean: 1.64).

Of the 36 pharmacists that enrolled, 64\% (23/36) graduated from pharmacy school after 2000, with $81 \%(29 / 36)$ earning a Doctor of Pharmacy degree (see Table 1). Half of the participating pharmacists were the pharmacy owner or pharmacist in charge (PIC).

Pharmacist participants recruited and offered PGx testing to 151 patient participants; there was one incomplete dataset yielding an analyzable dataset of 150 participants. Sixty percent of patient participants were female, $90.0 \%$ were White, and the mean age was 61 years. Of the 10 drugs for which testing was available, three drugs accounted for $60 \%$ of the medications prescribed to participants: metoprolol (29\%), citalopram (18\%), and aripiprazole (13\%). Further description of the patient participants are included in a separate publication.

\section{Pharmacy Setting}

Overall, a total of $23(64 \%)$ of the participating pharmacists estimated that their pharmacy filled between 100 and
300 prescriptions per week, four pharmacists (11\%) estimated that their pharmacy filled between 400 and 500 prescriptions, three (8\%) estimated less than 100 prescriptions and six (17\%) estimated more than 500 prescriptions weekly. All of the pharmacists reported that their pharmacies offered additional services, with almost half (17/36) offering at least five additional services. Among the most common additional services offered were immunizations, MTM, compounding, disease state management, and sale of durable medical equipment. Thirty-four pharmacists (94\%) reported that their pharmacy had a separate patient area to provide counseling to patients.

\section{Pharmacist Practice and Education}

The average number of years in pharmacy practice was 11.1 years and median of 9.5 (range: 0-28 years). For pharmacy owners/PIC, the median number of years in practice was 15.5 (mean: 15.4; range: 2-28), while for staff and consultant pharmacists, the median years in practice was four years (mean: 6.8; range: 0-22). Sixty-nine percent had not completed any type of educational program in personalized

Table I Summary of Demographic Data of Pharmacist Participants

\begin{tabular}{|c|c|c|c|c|c|c|}
\hline & $\begin{array}{l}\text { Pre-Study } \\
\text { Survey }(n=36) \\
(\%)\end{array}$ & & & $\begin{array}{l}\text { Post-Study } \\
\text { Survey } \\
(\mathrm{N}=16)\end{array}$ & & \\
\hline & (AII) & $\begin{array}{l}\text { PGx Only } \\
\text { Arm }(n=15)\end{array}$ & $\begin{array}{l}\text { PGx + MTM } \\
\text { Arm }(n=2 I)\end{array}$ & (AII) & $\begin{array}{l}\text { PGx Only } \\
\text { Arm }(n=7)\end{array}$ & $\begin{array}{l}\text { PGx + MTM } \\
\text { Arm }(n=9)\end{array}$ \\
\hline $\begin{array}{l}\text { Highest Completed Degree } \\
\text { - B.S. in Pharmacy } \\
\text { - Doctor of Pharmacy }\end{array}$ & $\begin{array}{l}7(19.4) \\
29(80.6)\end{array}$ & $\begin{array}{l}4(26.7) \\
\text { II (73.3) }\end{array}$ & $\begin{array}{l}3(14.3) \\
18(85.7)\end{array}$ & $\begin{array}{l}3(18.8) \\
13(81.3)\end{array}$ & $\begin{array}{l}2(28.6) \\
5 \text { (7I.4) }\end{array}$ & $\begin{array}{l}\text { I (II.I) } \\
8(88.9)\end{array}$ \\
\hline $\begin{array}{l}\text { Graduation Year } \\
\text { - } 198 \mid-90 \\
\text { - } 1991-2000 \\
\text { - After } 2000\end{array}$ & $\begin{array}{l}3(8.3) \\
10(27.8) \\
23(63.9)\end{array}$ & $\begin{array}{l}\text { I }(6.7) \\
3(20.0) \\
\text { I I (73.3) }\end{array}$ & $\begin{array}{l}2(9.5) \\
7(33.3) \\
12(57.1)\end{array}$ & $\begin{array}{l}\text { I (6.3) } \\
5(3 \mid .3) \\
10(62.5)\end{array}$ & $\begin{array}{l}0 \\
2(28.6) \\
5(71.4)\end{array}$ & $\begin{array}{l}I(11.1) \\
3(33.3) \\
5(55.6)\end{array}$ \\
\hline $\begin{array}{l}\text { Average Total Number of } \\
\text { Years in Pharmacy Practice }\end{array}$ & $\begin{array}{l}\text { I I.I (range 0-28; } \\
\text { median: 9.5) }\end{array}$ & $\begin{array}{l}\text { 10.1 (range 2- } \\
\text { 26; median: 9) }\end{array}$ & $\begin{array}{l}\text { II.9 (range 0- } \\
\text { 28; median: 10) }\end{array}$ & $\begin{array}{l}\text { II (range 0-28; } \\
\text { median: 10) }\end{array}$ & $\begin{array}{l}8.9 \text { (range 2- } \\
\text { 23; median: 4) }\end{array}$ & $\begin{array}{l}\text { I2.7 (range 0- } \\
\text { 28; median: 13) }\end{array}$ \\
\hline $\begin{array}{l}\text { Job Title } \\
\text { - Pharmacy owner/ } \\
\text { Pharmacist in Charge (PIC) } \\
\text { - Staff Pharmacist } \\
\text { - Consultant Pharmacist }\end{array}$ & $\begin{array}{l}18(50.0) \\
16(44.4) \\
2(5.6)\end{array}$ & $\begin{array}{l}10(66.7) \\
4(26.7) \\
1(6.7)\end{array}$ & $\begin{array}{l}8(38.1) \\
12(57.1) \\
1(4.8)\end{array}$ & $\begin{array}{l}7(43.8) \\
8(50.0) \\
I(6.3)\end{array}$ & $\begin{array}{l}4(57.1) \\
2(28.6) \\
1(14.3)\end{array}$ & $\begin{array}{l}3(33.3) \\
6(66.7) \\
0\end{array}$ \\
\hline $\begin{array}{l}\text { Ordered PGx Testing prior to } \\
\text { study } \\
\text { Completed a Course/ } \\
\text { workshop on PGx prior to } \\
\text { study }\end{array}$ & $\begin{array}{l}4(\mathrm{I} I . \mathrm{I}) \\
\mathrm{I} I(30.6)\end{array}$ & $\begin{array}{l}2(13.3) \\
5(33.3)\end{array}$ & $\begin{array}{l}2(9.5) \\
6(28.6)\end{array}$ & $\begin{array}{l}2(12.5) \\
7(43.8)\end{array}$ & $\begin{array}{l}\text { I (14.3) } \\
3(42.9)\end{array}$ & $\begin{array}{l}\text { I (II.I) } \\
4(44.4)\end{array}$ \\
\hline
\end{tabular}


medicine or PGx prior to attending the continuing education session required of this study. Of the 11 pharmacists who had some education in personalized medicine or PGx, seven (64\%) had graduated after 2000, and eight (73\%) had completed the training within the past 12 months. Overall, eighty-six (31/36) of participating pharmacists had never ordered a PGx test prior to this study.

Forty-seven percent (17/36) pharmacists had participated in an MTM Certificate training program developed by APhA or another accredited organization. Ninety-two percent (33/36) of pharmacists reported that they have provided MTM services at their current or prior pharmacy, with an average of 10 MTM services provided weekly.

\section{Pharmacist Knowledge of PGx}

In the pre-study survey $(n=36)$, the average number of questions answered correctly in the seven-question PGx knowledge assessment was 5.4 (median: 5; range: 3-7). We hypothesized that pharmacists who had graduated more recently (in 2000 or after) would score higher, but we did not observe a significant difference in scores $(p=0.39)$. If limited to pharmacists who completed both the pre and post-study surveys $(n=16)$, the average correct score at baseline was 5.4 (median: 6; range: 4-7). In the post-study survey, the average number of correctly answered questions was 6.3 (median: 6; range: 5-7), significantly higher compared to the pre-study assessment $(p=0.018)$ (Table 2). It is possible that pharmacists used other resources to complete the post-study assessment as we did not explicitly request that they not. We did not observe any significant change in the number of correctly answered questions by study arm.

Table 2 Number of Correctly Answered Questions on Knowledge Assessment by Study Arm (Pre-Study vs Post-Study)

\begin{tabular}{|l|l|l|l|l|}
\hline $\begin{array}{l}\text { Number of } \\
\text { Correctly Answered } \\
\text { Questions }\end{array}$ & \multicolumn{2}{|c|}{$\begin{array}{c}\text { Pre-Study } \\
\text { Assessment } \\
(n=16)\end{array}$} & \multicolumn{2}{c|}{$\begin{array}{c}\text { Post-Study } \\
\text { Assessment } \\
\text { (n=16) }\end{array}$} \\
\hline & $\begin{array}{l}\text { PGx } \\
\text { Only } \\
(\mathbf{N}=7)\end{array}$ & $\begin{array}{l}\text { PGx } \\
+ \text { MTM } \\
(\mathbf{N}=9)\end{array}$ & $\begin{array}{l}\text { PGx } \\
\text { Only } \\
(\mathbf{N = 7})\end{array}$ & $\begin{array}{l}\text { PGx } \\
+ \text { MTM } \\
(\mathbf{N}=9)\end{array}$ \\
\hline Mean (SD) & $\begin{array}{l}5.43 \\
(0.787)\end{array}$ & $\begin{array}{l}5.44 \\
(1.01)\end{array}$ & $\begin{array}{l}6.29 \\
(0.756)\end{array}$ & $\begin{array}{l}6.33 \\
(0.500)\end{array}$ \\
\hline Median [Min, Max] & 6.00 & 6.00 & 6.00 & 6.00 \\
& {$[4.00$,} & {$[4.00$,} & {$[5.00$,} & {$[6.00$,} \\
& $6.00]$ & $7.00]$ & $7.00]$ & $7.00]$ \\
\hline
\end{tabular}

\section{Utilization of Patient Educational}

\section{Resources}

We provided pharmacists with a toolkit of four patient educational resources (an information sheet, flipbook, summary results page and wallet card) that could be used initially to discuss PGx and again when communicating results of testing. ${ }^{27}$ Based on the information provided in the logbook per each enrolled participant, pharmacists reported using at least one of the four educational resources made available to them for $86.7 \%$ of enrolled participants (130/150) and used two or more for 39.3\% (59/150) of participants (see Table 3). Of those who used one or more of the educational tools $(n=130)$, the most commonly used toolkit component was the results summary sheet $(60.8 \% ; 79 / 130)$, followed by the test information sheet $(50.0 \%$; 65/130). Pharmacists in the PGx only test arm were significantly more likely to use at least one of the educational resources than pharmacists in the PGx test plus MTM arm $(p=0.007)$. Pharmacists in the PGx only test arm were also significantly more likely to have used the test information sheet $(p<0.001)$, but no difference was observed for any of the other toolkit resources.

\section{Pharmacist Confidence}

In the post-study survey, pharmacists overall indicated that they agreed or strongly agreed that they felt qualified/able to provide PGx testing at their pharmacy. Almost all pharmacists indicated that they agreed or strongly agreed with each of the following statements: 1) they felt confident in their ability to provide counseling to patients regarding the results of their PGx testing and the impact on their drug therapy $(93.8 \%) ; 2)$ they could make recommendations to physicians based on the PGx test results regarding drug therapy changes $(93.8 \%)$; 3) they have sufficient time to provide recommendations to physicians on the personalization of patient medication regimens (87.5\%); and 4) PGx testing would improve compliance with drug regimens $(87.5 \%)$. Most pharmacists strongly or somewhat agreed with the statement that most patients would be interested in PGx testing (93.8\%).

\section{Perceived Burden to Current Practice and Continuation of PGx Testing}

Based on a review of the logbook submitted for each participant, the average number of tasks carried out by the pharmacist from the initial discussion with the patient to the final discussion or consultation with the prescriber 
Table 3 Pharmacist Utilization of Educational Resources by Study Arm

\begin{tabular}{|l|l|l|l|}
\hline & $\begin{array}{l}\text { PGx Test Only Study Arm (n=67) } \\
\text { (\%) }\end{array}$ & $\begin{array}{l}\text { PGx Test + MTM Study Arm (n=83) } \\
\text { (\%) }\end{array}$ & $\begin{array}{l}\text { Total (N=150) } \\
(\%)\end{array}$ \\
\hline $\begin{array}{l}\text { Number of Educational Resources } \\
\text { Used }\end{array}$ & & & \\
- Mean & $1.6(0.87)$ & $1.24(0.91)$ & $1.4(0.91)$ \\
- Median (Range) & $2.0(0-4)$ & $1.0(0-4)$ & $1.0(0-4)$ \\
\hline Specific Educational Resource Used* & & & $20(13.3)$ \\
- None & $6(9.0)$ & $14(16.9)$ & $65(43.3)$ \\
- Test Info Sheet & $41(61.2)$ & $24(28.9)$ & $50(33.3)$ \\
- Flipbook & $22(32.8)$ & $28(33.7)$ & $79(52.7)$ \\
- Results Summary Sheet & $37(55.2)$ & $9(10.8)$ & $16(10.7)$ \\
- Results Wallet Card & $7(10.4)$ & & \\
\hline
\end{tabular}

Note: *Numbers will be greater than total number due to use of more than one educational resource.

was 7.4 (range: $2-13$ ). There was no significant difference in the number of tasks reported between the study arms. We also coded the type of activity (patient or providerrelated) and when the activity occurred (pre- and posttesting). Overall, there was a significantly higher number of pre-testing activities (mean: 4.9; range: 1-11) compared to post-testing activities (mean: 2.4; range: 0-6) $(\mathrm{p}<0.0001)$. Again, no significant difference in the number of pre-testing or post-testing activities was observed between study arms. An average of 5.1 (range: 1-10) activities involved the patient and 2.3 (range: 0-7) involved the prescriber.

In the pre-study survey, pharmacists' greatest perceived barriers to providing PGx testing were lack of reimbursement for testing $(25 \%)$, inadequate of pharmacogenetics knowledge (17\%), and insufficient time to provide PGx testing (14\%). In the post-study survey, the greatest perceived barrier reported was still lack of reimbursement for testing (56\%), followed by lack of reimbursement for pharmacist counseling and test interpretation (25\%), and poor acceptance of recommendations based on the test results by physicians $(12.5 \%)$.

Following the completion of the study, $75 \%$ of pharmacists overall indicated that they may continue to provide PGx testing at their pharmacy after the study. Two pharmacists, both from the PGx plus MTM arm, indicated that they definitely would. Two pharmacists, one from each arm, indicated that they definitely would not continue to provide PGx testing.

\section{Interview Themes}

A total of four pharmacists participated in the interview (one each from the PGx testing only and MTM-PGx arm; the other two did not specify). The major challenge raised by all pharmacists was timely provider response to complete and return the test authorization form and connecting with providers to review the test results. Pharmacists typically did not hear from physicians after faxing the test report, even for patients with a recommendation to change prescription based on test result. Two pharmacists attributed physicians' lack of interest to their unfamiliarity with PGx testing.

The pharmacists agreed that patients appeared much more interested in the testing and results than their health providers. Some of the specific comments regarding patient interest were patient unawareness that such a test existed, that it could explain individual differences in drug response, and surprise that it could be performed with a buccal swab instead of a blood draw. However, multiple pharmacists mentioned the issue of health literacy and uncertainty about how much the patients understood about testing. The educational flipbook provided by the study team was used to not only introduce the test (time permitting), but also to review the results. The format enabled pharmacists to have a structured discussion and also ensure that they did not overlook any key points. Pharmacists reported difficulty re-contacting patients to discuss the test results and would discuss results over the phone instead of delaying for an in-person visit.

While the interviewed pharmacists indicated that they had learned a lot from participating in the study and were interested in continuing to offer PGx testing, it was not likely feasible from a resource standpoint. Some believed that their customers who could afford to pay for PGx testing would likely want to undergo testing, but 
a substantial proportion were covered by Medicaid and Medicare and this option would not be feasible for them. Therefore, without insurer coverage for testing, the effort to establish a relationship with a testing laboratory to offer the service would not be considered worthwhile for a handful of patients each year they projected. From a workflow perspective, it was not perceived onerous (no more so than offering a flu shot).

\section{Discussion}

Clinical investigation on PGx testing continues to address questions about clinical utility and limited evidence basis, ${ }^{28}$ the role of other factors that may contribute to development of adverse responses or limited efficacy, or pharmacoresistance, ${ }^{29-32}$ and inconsistencies between clinical laboratory testing platforms, variant interpretation, and clinical guidelines. ${ }^{33-38}$ However, much attention has focused on provider preparedness to deliver and integrate single-gene PGx testing into clinical care, including pharmacist preparedness. ${ }^{39,40}$ Pharmacists in particular have played a leading role in the development and implementation of PGx testing at academic medical centers and large health systems. ${ }^{3}$ However, the permeation of testing at the community and local level is likely uneven and limited compared to large health systems. In this pragmatic trial, we examined the feasibility of delivering PGx testing in an independent community pharmacy setting and specifically explored community pharmacists' preparedness and attitudes toward offering PGx testing. We found that despite the majority of pharmacists having had no special training in PGx, they scored fairly high on the pre-study knowledge survey and performed significantly higher on the post-study survey. Many expressed high levels of confidence in their ability to deliver PGx testing, communicate with patients, and work with prescribers to appropriately act upon the results following participation in the study, similar to positive outcomes reported in other PGx studies with community pharmacists. ${ }^{16,41,42}$ However, the issue of reimbursement remained a key barrier to continuing to offer testing, noted in other pharmacist studies as well. ${ }^{14,16}$

At the start of the study, pharmacist time and knowledge were also noted as potential barriers prior, though the responses shifted towards lack of reimbursement for pharmacist counseling and test interpretation, and poor acceptance of recommendations based on the test results by physicians at the conclusion of the study. Although the effort/time required was not noted as a barrier by pharmacists in the interviews, the lack of response from providers was repeatedly highlighted as problematic. A working relationship between pharmacists and providers may facilitate more acceptance and trust to implement new clinical applications such as PGx testing. Pharmacists regularly communicate with providers daily, are well-experienced working as a collaborative team, and have partnered in ordering and consulting on other types of clinical testing. ${ }^{43}$ Communication between providers and pharmacists is often by facsimile ${ }^{44}$ or through e-prescribing, although some independent community pharmacies have access to electronic health systems of local health systems allowing for integrated care. Despite the increase in the number of package inserts with PGx information ${ }^{1}$ and guidelines from CPIC and DPWG, many providers are likely unaware of this information specifically and/or have limited understanding of PGx testing in general. ${ }^{40,45-48}$ Providers who are not aware or knowledgeable about PGx testing or have doubts about the clinical benefits of testing may have be reluctant to authorize testing or change prescriptions, which may have accounted for the muted response experienced by the pharmacists in this study. In other studies (though not in community pharmacy settings), the addition of PGx test results improved or resulted in high physician acceptance of pharmacist recommendations. ${ }^{49,50}$

In addition to concerns about reimbursement, impact on delivery of other pharmacy services, and workforce constraints, which can all result in a slower adoption of PGx testing at the community level, there may also be differences between pharmacy settings that contribute to inconsistent rollout of PGx testing at the community pharmacy level. In particular, chain-based pharmacists may be able to provide the clinical decision support systems not feasible at independent pharmacies and also have more patient resources available in convenient formats like videos that would reduce the face-to-face time for counseling and patient education. On the other hand, busy retail community pharmacies may not be able to provide MTM or in-depth PGx counseling due to the additional time requirements. While independent community pharmacists may have more flexibility to offer new services compared to chain-based pharmacists, they may also be more constrained by economic limitations. With the presence of onsite clinics in pharmacy retail settings (eg, CVS' Minute Clinics), additional opportunities to implement PGx testing by the pharmacist with a closer relationship with prescribing providers may arise. In addition to reimbursement and time concerns, state guidelines regarding test ordering authority and pharmacist training are among the primary 
issues to be addressed to enable PGx testing to be offered widely by pharmacists. ${ }^{14,51,52}$ Direct-to-consumer PGx testing may also significantly increase the role of pharmacists as patients may consult with them to better understand their test results and how it impacts their current medications. $^{53,54}$

Several limitations of the data should be noted. The participating pharmacists were all based in independent community pharmacies practicing in North Carolina, and may not represent other types of pharmacies or those based in other states. In addition, the sample size was small and of limited diversity. We lacked data about business models and overarching care models of the pharmacies that would inform the sustainability of offering PGx testing as well as other important factors such as pharmacists' background and training, pharmacist effort and time, additional resources required to offer PGx testing after the study.

As many groups have learned or experienced, implementing PGx testing is a huge undertaking with multiple challenges. $^{33,55,56}$ Pharmacists can play a substantial role in identifying eligible patients, providing patient counseling before and after testing, sample collection and shipment, results interpretation, and communication with prescribers. Some of the barriers identified in this study can be addressed through increasing prescribers' awareness, development of patient-friendly educational resources on various topics to promote informed decisionmaking and reduce pharmacist time, and tools to interpret and apply the PGx test results. Further consideration of pharmacy business models and reimbursement mechanisms are also needed to advance inclusion of PGx testing in community pharmacy settings.

\section{Data Sharing Statement}

The raw data set used for this study is offered by the corresponding author (Susanne.haga@duke.edu) upon reasonable request.

\section{Acknowledgment}

This study was funded by the US National Institutes of Health (R01GM081416).

\section{Disclosure}

Dr Susanne B Haga report grants from US National Institutes of Health, during the conduct of the study. Dr Deepak Voora report grants from NIH, during the conduct of the study; personal fees from Optum, outside the submitted work. The authors report no other conflicts of interest in this work.

\section{References}

1. U.S. Food and Drug Administration. Table of pharmacogenomic biomarkers in drug labeling. 2021. Available from: https://www.fda. gov/drugs/science-and-research-drugs/table-pharmacogenomicbiomarkers-drug-labeling. Accessed June 6, 2021.

2. Haga SB, Moaddeb J. Comparison of delivery strategies for pharmacogenetic testing services. Pharmacogenet Genomics. 2014;24 (3):139-145. doi:10.1097/FPC.0000000000000028

3. Nagy M, Eirini Tsermpini E, Siamoglou S, Patrinos GP. Evaluating the current level of pharmacists' pharmacogenomics knowledge and its impact on pharmacogenomics implementation. Pharmacogenomics. 2020;21(16):1179-1189. doi:10.2217/pgs-2020-0076

4. Owusu-Obeng A, Weitzel KW, Hatton RC, et al. Emerging roles for pharmacists in clinical implementation of pharmacogenomics. Pharmacotherapy. 2014;34(10):1102-1112. doi:10.1002/phar.1481

5. American Society of Health-System Pharmacists. ASHP statement on the pharmacist's role in clinical pharmacogenomics. Am J Health Syst Pharm. 2015;72(7):579-581. doi:10.2146/sp150003

6. Wang YT, Merl MY, Yang J, Zhu ZX, Li GH. Opportunities for pharmacists to integrate pharmacogenomics into clinical practice. Pharmacogenomics J. 2020;20(2):169-178. doi:10.1038/s41397019-0119-8

7. Roederer MW, Kuo GM, Kisor DF, et al. Pharmacogenomics competencies in pharmacy practice: a blueprint for change. $J$ Am Pharm Assoc. 2017;57(1):120-125. doi:10.1016/j.japh.2016.08.014

8. Crown N, Sproule BA, Luke MJ, Piquette-Miller M, McCarthy LM. A continuing professional development program for pharmacists implementing pharmacogenomics into practice. Pharmacy. 2020;8 (2). doi:10.3390/pharmacy 8020055

9. Formea CM, Nicholson WT, Vitek CR, et al. Implementation of a pharmacogenomics education program for pharmacists. Am $J$ Health Syst Pharm. 2018;75(23):1939-1946. doi:10.2146/ ajhp170771

10. Accreditation Council for Pharmacy Education. Accreditation standards and guidelines: professional program in pharmacy leading to the doctor of pharmacy degree. 2016. Available from: https://www. acpe-accredit.org/pdf/Standards2016FINAL.pdf. Accessed January 3, 2021.

11. Karuna N, Tragulpiankit P, Mahasirimongkol S, Chumnumwat S. Knowledge, attitude, and practice towards pharmacogenomics among hospital pharmacists in Thailand. Pharmacogenet Genomics. 2020;30(4):73-80. doi:10.1097/FPC.0000000000000399

12. Roederer M, Van Riper M, Valgus J, Knafl G, McLeod H. Knowledge, attitudes and education of pharmacists regarding pharmacogenetic testing. Per Med. 2012;9(1):19-27. doi:10.2217/ pme.11.87

13. Petit C, Croisetière A, Chen F, Laverdière I. Are pharmacists from the province of Quebec ready to integrate pharmacogenetics into their practice. Pharmacogenomics. 2020;21(4):247-256. doi:10.2217/pgs2019-0144

14. Alexander KM, Divine HS, Hanna CR, Gokun Y, Freeman PR. Implementation of personalized medicine services in community pharmacies: perceptions of independent community pharmacists. $J$ Am Pharm Assoc. 2014;54(5):510-517. doi:10.1331/ JAPhA.2014.13041

15. Cavallari LH, Lee CR, Duarte JD, et al. Implementation of inpatient models of pharmacogenetics programs. Am J Health Syst Pharm. 2016;73(23):1944-1954. doi:10.2146/ajhp150946

16. Ferreri SP, Greco AJ, Michaels NM, et al. Implementation of a pharmacogenomics service in a community pharmacy. $J \mathrm{Am}$ Pharm Assoc. 2014;54(2):172-180. doi:10.1331/JAPhA.2014.13033 
17. Schuh MJ, Crosby S. Description of an established, fee-for-service, office-based, pharmacist-managed pharmacogenomics practice. $\mathrm{Sr}$ Care Pharm. 2019;34(10):660-668. doi:10.4140/TCP.n.2019.660

18. Dorfman R, London Z, Metias M, Kabakchiev B, Mukerjee G, Moser A. Individualized medication management in Ontario long-term care clinical impact on management of depression, pain, and dementia. J Am Med Dir Assoc. 2020;21(6):823-829.e825. doi:10.1016/j.jamda.2020.04.009

19. Arwood MJ, Dietrich EA, Duong BQ, et al. Design and early implementation successes and challenges of a pharmacogenetics consult clinic. J Clin Med. 2020;9(7):2274. doi:10.3390/jcm9072274

20. Nutescu EA, Drozda K, Bress AP, et al. Feasibility of implementing a comprehensive warfarin pharmacogenetics service. Pharmacotherapy. 2013;33(11):1156-1164. doi:10.1002/phar.1329

21. Reiss SM. Integrating pharmacogenomics into pharmacy practice via medication therapy management. J Am Pharm Assoc. 2011;51(6): e64-74. doi:10.1331/JAPhA.2011.11543

22. Brown JT, MacDonald D, Yapel A, Luczak T, Hanson A, Stenehjem DD. Integrating pharmacogenetic testing via medication therapy management in an outpatient family medicine clinic. Pharmacogenomics. 2021;22(4):203-212. doi:10.2217/pgs-2020-0178

23. Klomp SD, Manson ML, Guchelaar HJ, Swen JJ. Phenoconversion of cytochrome P450 metabolism: a systematic review. J Clin Med. 2020;9(9):2890. doi:10.3390/jcm9092890

24. Bain KT, Knowlton $\mathrm{CH}$, Matos A. Cost avoidance related to a pharmacist-led pharmacogenomics service for the program of all-inclusive care for the elderly. Pharmacogenomics. 2020;21 (10):651-661. doi:10.2217/pgs-2019-0197

25. Lee YM, Manzoor BS, Cavallari LH, Nutescu EA. Facilitators and barriers to the adoption of pharmacogenetic testing in an inner-city population. Pharmacotherapy. 2018;38(2):205-216. doi:10.1002/ phar.2077

26. Haga SB, Moaddeb J, Mills R, Voora D. Assessing feasibility of delivering pharmacogenetic testing in a community pharmacy setting. Pharmacogenomics. 2017;18(4):327-335. doi:10.2217/pgs-2016-0175

27. Haga SB, Mills R, Moaddeb J. Evaluation of a pharmacogenetic educational toolkit for community pharmacists. Pharmacogenomics. 2016;17(14):1491-1502. doi:10.2217/pgs-2016-0002

28. Janssens AC, Deverka PA. Useless until proven effective: the clinical utility of preemptive pharmacogenetic testing. Clin Pharmacol Ther. 2014;96(6):652-654. doi:10.1038/clpt.2014.186

29. Clarke G, Sandhu KV, Griffin BT, Dinan TG, Cryan JF, Hyland NP. Gut reactions: breaking down xenobiotic-microbiome interactions. Pharmacol Rev. 2019;71(2):198-224. doi:10.1124/pr.118.015768

30. Koppel N, Maini Rekdal V, Balskus EP. Chemical transformation of xenobiotics by the human gut microbiota. Science. 2017;356:6344. doi:10.1126/science.aag2770

31. Janmohamed M, Brodie MJ, Kwan P. Pharmacoresistance Epidemiology, mechanisms, and impact on epilepsy treatment. Neuropharmacology. 2020;168:107790. doi:10.1016/j. neuropharm.2019.107790

32. Zhou J, Li M, Wang X, et al. Drug response-related DNA methylation changes in schizophrenia, bipolar disorder, and major depressive disorder. Front Neurosci. 2021;15:674273. doi:10.3389/ fnins.2021.674273

33. Moyer AM, Caraballo PJ. The challenges of implementing pharmacogenomic testing in the clinic. Expert Rev Pharmacoecon Outcomes Res. 2017;17(6):567-577. doi:10.1080/14737167.2017.1385395

34. Kalman LV, Agundez J, Appell ML, et al. Pharmacogenetic allele nomenclature: international workgroup recommendations for test result reporting. Clin Pharmacol Ther. 2016;99(2):172-185. doi:10.1002/cpt.280

35. Bank PCD, Caudle KE, Swen JJ, et al. Comparison of the guidelines of the clinical pharmacogenetics implementation consortium and the Dutch pharmacogenetics working group. Clin Pharmacol Ther. 2018;103(4):599-618. doi:10.1002/cpt.762
36. Koutsilieri S, Tzioufa F, Sismanoglou DC, Patrinos GP. Unveiling the guidance heterogeneity for genome-informed drug treatment interventions among regulatory bodies and research consortia. Pharmacol Res. 2020;153:104590. doi:10.1016/j. phrs.2019.104590

37. Shugg T, Pasternak AL, London B, Luzum JA. Prevalence and types of inconsistencies in clinical pharmacogenetic recommendations among major U.S. sources. NPJ Genom Med. 2020;5:48. doi:10.1038/s41525-020-00156-7

38. Caudle KE, Keeling NJ, Klein TE, Whirl-Carrillo M, Pratt VM, Hoffman JM. Standardization can accelerate the adoption of pharmacogenomics: current status and the path forward. Pharmacogenomics. 2018;19(10):847-860. doi:10.2217/pgs-2018-0028

39. Amara N, Blouin-Bougie J, Bouthillier D, Simard J. On the readiness of physicians for pharmacogenomics testing: an empirical assessment. Pharmacogenomics J. 2018;18(2):308-318. doi:10.1038/tpj.2017.22

40. Haga SB. Primary care physicians' knowledge of and experience with pharmacogenetic testing. Pharmgenomics Pers Med. 2012;82 (4):388-394.

41. Moaddeb J. Community pharmacists' experience with pharmacogenetic testing. Pharmacogenomics. 2015;55(6):587-594.

42. Breaux S, Desrosiers FAD, Neira M, Sinha S, Nislow C. Pharmacogenomics at the point of care: a community pharmacy project in British Columbia. J Pers Med. 2020;11(1):11. doi:10.3390/jpm11010011

43. Bacci JL, Klepser D, Tilley H, Smith JK, Klepser ME. Community pharmacy-based point-of-care testing: a case study of pharmacist-physician collaborative working relationships. Res Social Adm Pharm. 2018;14(1):112-115. doi:10.1016/j. sapharm.2016.12.005

44. Renfro CP, Robinson JM, Turner K, Gaskins T, Ferreri SP. Care coordination and follow-up practices in the community pharmacy setting: a mixed methods study. J Am Pharm Assoc (2003). 2020;60 (4):631-638.e2. doi:10.1016/j.japh.2019.11.023

45. Stanek EJ, Sanders CL, Taber KA, et al. Adoption of pharmacogenomic testing by US physicians: results of a nationwide survey. Clin Pharmacol Ther. 2012;91(3):450-458. doi:10.1038/ clpt.2011.306

46. Deininger KM, Tsunoda SM, Hirsch JD, et al. National survey of physicians' perspectives on pharmacogenetic testing in solid organ transplantation. Clin Transplant. 2020;34(10):e14037. doi:10.1111/ ctr. 14037

47. Liko I, Lee YM, Stutzman DL, et al. Providers' perspectives on the clinical utility of pharmacogenomic testing in pediatric patients. Pharmacogenomics. 2021;22(5):263-274. doi:10.2217/pgs-2020-0112

48. Kim WY, Kim HS, Oh M, Shin JG. Survey of physicians' views on the clinical implementation of pharmacogenomics-based personalized therapy. Transl Clin Pharmacol. 2020;28(1):34-42. doi:10.12793/ tcp.2020.28.e6

49. Kim K, Magness JW, Nelson R, Baron V, Brixner DI. Clinical utility of pharmacogenetic testing and a clinical decision support tool to enhance the identification of drug therapy problems through medication therapy management in polypharmacy patients. J Manag Care Spec Pharm. 2018;24(12):1250-1259. doi:10.18553/ jmcp.2018.24.12.1250

50. Bain KT, Schwartz EJ, Knowlton OV, Knowlton CH, Turgeon J. Implementation of a pharmacist-led pharmacogenomics service for the program of all-inclusive care for the elderly (PHARM-GENOME-PACE). J Am Pharm Assoc (2003). 2018;58 (3):281-289.e281. doi:10.1016/j.japh.2018.02.011

51. Gubbins PO, Klepser ME, Dering-Anderson AM, et al. Point-of-care testing for infectious diseases: opportunities, barriers, and considerations in community pharmacy. J Am Pharm Assoc (2003). 2014;54 (2):163-171. doi:10.1331/JAPhA.2014.13167 
52. Gubbins PO, Klepser ME, Adams AJ, Jacobs DM, Percival KM, Tallman GB. Potential for pharmacy-public health collaborations using pharmacy-based point-of-care testing services for infectious diseases. J Public Health Manag Pract. 2017;23(6):593-600. doi:10.1097/PHH.0000000000000482

53. Gammal RS, Mayes J, Caudle KE. Ready or not, here it comes: direct-to-consumer pharmacogenomic testing and its implications for community pharmacists. J Am Pharm Assoc (2003). 2019;59 (5):646-650. doi:10.1016/j.japh.2019.06.008

54. Kisor DF, Petry NJ, Bright DR. Pharmacogenomics in the United States community pharmacy setting: the clopidogrel-CYP2C19 example. Pharmgenomics Pers Med. 2021;14:569-577. doi:10.2147/PGPM.S224894
55. Cicali EJ, Weitzel KW, Elsey AR, et al. Challenges and lessons learned from clinical pharmacogenetic implementation of multiple gene-drug pairs across ambulatory care settings. Genet Med. 2019;21(10):2264-2274. doi:10.1038/s41436-019-0500-7

56. Ramsey LB, Prows CA, Zhang K, et al. Implementation of pharmacogenetics at Cincinnati Children's hospital medical center: lessons learned over 14 years of personalizing medicine. Clin Pharmacol Ther. 2019;105(1):49-52. doi:10.1002/cpt.1165

\section{Publish your work in this journal}

Pharmacogenomics and Personalized Medicine is an international, peer-reviewed, open access journal characterizing the influence of genotype on pharmacology leading to the development of personalized treatment programs and individualized drug selection for improved safety, efficacy and sustainability. This journal is indexed on the American Chemical Society's Chemical Abstracts Service (CAS). The manuscript management system is completely online and includes a very quick and fair peer-review system, which is all easy to use. Visit http://www.dovepress.com/testimonials.php to read real quotes from published authors. 